\title{
Regime shifts and heterogeneous trends in malaria time series from Western Kenya Highlands
}

\author{
LUIS FERNANDO CHAVES ${ }^{1,2}$, MASAHIRO HASHIZUME ${ }^{3}$, AKIKO SATAKE ${ }^{1}$ \\ and NOBORU MINAKAWA ${ }^{3}$ \\ ${ }^{1}$ Graduate School of Environmental Sciences and Global Center of Excellence Program on Integrated Field Environmental \\ Science, Hokkaido University, Sapporo, Fapan \\ ${ }^{2}$ Programa de Investigación en Enfermedades Tropicales, Escuela de Medicina Veterinaria, Universidad Nacional, Heredia, \\ Costa Rica \\ ${ }^{3}$ Institute of Tropical Medicine (NEKKEN) and Global Center of Excellence Program on Tropical and Emergent Infectious \\ Diseases, Nagasaki University, Nagasaki, Fapan
}

(Received 4 May 2011; revised 2 June and 18 August 2011; accepted 25 August 2011; first published online 14 October 2011)

SUMMARY

Large malaria epidemics in the East African highlands during the mid and late 1990s kindled a stream of research on the role that global warming might have on malaria transmission. Most of the inferences using temporal information have been derived from a malaria incidence time series from Kericho. Here, we report a detailed analysis of 5 monthly time series, between 15 and 41 years long, from West Kenya encompassing an altitudinal gradient along Lake Victoria basin. We found decreasing, but heterogeneous, malaria trends since the late 1980 s at low altitudes $(<1600 \mathrm{~m})$, and the early 2000 s at high altitudes $(>1600 \mathrm{~m})$. Regime shifts were present in 3 of the series and were synchronous in the 2 time series from high altitudes. At low altitude, regime shifts were associated with a shift from increasing to decreasing malaria transmission, as well as a decrease in variability. At higher altitudes, regime shifts reflected an increase in malaria transmission variability. The heterogeneity in malaria trends probably reflects the multitude of factors that can drive malaria transmission and highlights the need for both spatially and temporally fine-grained data to make sound inferences about the impacts of climate change and control/elimination interventions on malaria transmission.

Key words: time series, breakpoint, Plasmodium, Kericho, Kapsabet, Kisii, Kisumu, Maseno, Kendu Bay, climate change, seasonal autoregressive.

\section{INTRODUCTION}

Large malaria epidemics in the East African highlands during the mid and late 1990s triggered a number of inquiries into the role that global warming might have on malaria transmission. Several authors proposed that spread of malaria into areas that rarely saw malaria transmission could be related to the impacts that small increases in temperature have on Plasmodium spp. development inside vectors (Lindsay and Birley, 1996; Patz and Olson, 2006). Traditionally considered a 'malaria-free' oasis inside a desert of high malaria transmission, the East African highlands are of special interest because of their geographical location (Lindsay and Martens, 1998). In particular, the role that climate change could have played on exacerbated malaria records in this area over recent years has been the focus of intensive research and debate (Chaves and Koenraadt, 2010).

\footnotetext{
* Corresponding author: Graduate School of Environmental Sciences, Hokkaido University, Suite A701, Kita-10, Nishi-5, Kita-Ku, Sapporo, Hokkai-do, 060-0810 Japan. Tel: +81117062267. Fax: +81 11706 4954. E-mail: lchaves@ees.hokudai.ac.jp
}

Studies from highland areas in Ethiopia, Tanzania, Kenya and Uganda have robustly shown signatures of climatic covariates on malaria time series (Abeku et al. 2004; Chaves and Koenraadt, 2010; Teklehaimanot et al. 2004; Zhou et al. 2004). A great deal of attention has been given to whether oscillations in the time series were intrinsically generated i.e., by the cyclic nature of immunity in growing populations (Hay et al. 2000), or were induced by exogenous factors (Pascual et al. 2008; Childs and Boots, 2010) and drug resistance (ArtzyRandrup et al. 2010). In addition, some studies have claimed to show that trends in temperature have driven the surge observed in transmission over recent years (Alonso et al. 2011). However, little attention has been given to the homogeneity/heterogeneity in transmission trends across the East African highlands, especially as revealed by time series analysis. In fact, most time series analyses have been exclusively focused on a time series from Kericho in Kenya (Hay et al. 2000; Hay et al. 2002a; Shanks et al. 2000, 2002, 2005; Pascual et al. 2008; Artzy-Randrup et al. 2010; Childs and Boots, 2010; Alonso et al. 2011). Several cross-sectional studies that examined transmission patterns across altitudinal gradients in the East African highlands reported an overall decrease in

Parasitology (2012), 139, 14-25. C Cambridge University Press 2011. The online version of this article is published within an Open Access environment subject to the conditions of the Creative Commons Attribution-NonCommercial-ShareAlike licence $<$ http://creativecommons. org/licenses/by-nc-sa/2.5/>. The written permission of Cambridge University Press must be obtained for commercial re-use. 
transmission with altitude (Bødker et al. 2003, 2006; Drakeley et al. 2005). Similar studies looking at several time series have tended to use coarsely grained data, for example, records from districts (Abeku et al. 2004; Teklehaimanot et al. 2004), hospital time series from distant locations (Zhou et al. 2004) or have mixed inpatient data, i.e., virulent cases admitted to a hospital, with outpatient data, i.e., febrile cases that visit the hospital but require no further attention in a hospital and not parasitologically confirmed (Zhou et al. 2004; Pascual and Bouma, 2009). Others have focused on showing the signatures of large-scale climatic phenomena such as the Indian Ocean Dipole (IOD) Mode on malaria transmission (Hashizume et al. 2009). However, further inquiries into the homogeneity of these trends, for example, whether the incidence is similarly increased or decreased through time, or is dependent on the existence and synchronicity of regime shifts, i.e., whether similar abrupt changes on the average and the variability of malaria incidence have been simultaneously observed in East Africa, has been out of the research agenda.

Here, we employ 5 time series from hospitals in the Lake Victoria basin region of Western Kenya, an area with well-defined and regionally homogeneous seasonal climatic patterns (Anyah and Semazzi, 2004; Anyah et al. 2006), and ask whether these time series show similar regime shifts. We also ask whether increasing transmission trends reported for Kericho (Shanks et al. 2000) are common to the whole Lake Victoria basin. We found that regime shifts, when present, were asynchronous along the altitude range but synchronous at high altitude. Trends in the time series also changed with altitude. At low altitudes, i.e., below $1500 \mathrm{~m}$, malaria incidence began to decrease in the late 1980s. By contrast, the variability and average of malaria transmission either kept constant or increased at higher altitudes, above $1600 \mathrm{~m}$, especially during the $1990 \mathrm{~s}$, and began to decrease in the early 2000s. Finally, our results highlight the need for both spatially and temporally fine-grained data to make sound inferences about the impacts of climate change and control/elimination interventions on malaria transmission.

\section{MATERIALS AND METHODS}

\section{Data}

Figure 1A shows the location of our study sites within Lake Victoria basin and the elevation range that they span. Time series data used in our study are monthly records of inpatients diagnosed with malaria in Maseno (Fig. 1B), Kendu Bay (Fig. 1C), Kisii (Fig. 1D), Kapsabet (Fig. 1E), Kericho (Fig. 1F). Figure 1 also shows monthly rainfall records for Kisumu (Fig. 1G), Kisii (Fig. 1H), Kapsabet (Fig. 1I), Kericho (Fig. 1J) and the dipole mode index (DMI, Fig. 1K) and El Niño 3 (ENSO,
Fig. 1L). The 5 malaria time series are monthly counts of inpatients admitted into the hospitals because of high fever and other clinical malaria symptoms. In Kericho, all malaria cases where confirmed by blood-slide examination (bse) (Hay et al. 2000; Shanks et al. 2000, 2002, 2005). In the other 4 sites (Maseno, Kendu Bay, Kisii and Kapsabet) we collected the data from books with malaria-diagnosed inpatient records. Unfortunately, these books did not indicate whether all recorded malaria cases were confirmed by bse. We were informed by staff members from each hospital that cases were often confirmed by bse, but hospital staff members were unable to guarantee a confirmation of all cases by such a method. However, in each hospital, staff members indicated that, to the best of their knowledge and experience, criteria for hospitalization of diagnosed malaria cases have been consistent through the years presented in this study. In summary, we selected these study sites because we were informed that no seasonal or secular changes in malaria diagnosis have occurred over the studied periods. In fact, with the exception of Maseno (Fig. 1B), our data did not include missing observations. We also focused on the analysis of cases from all ages to make sound comparisons with previous studies looking at trends, which have been based on a similar set of cases (Hay et al. 2000; Shanks et al. 2000; Abeku et al. 2004; Teklehaimanot et al. 2004; Zhou et al. 2004; Pascual et al. 2008; Pascual and Bouma, 2009; Artzy-Randrup et al. 2010; Childs and Boots, 2010; Alonso et al. 2011). In the analysis we do not include data for population growth because of the technical difficulties to estimate hospital catchment population, which will be the most desirable denominator to study impacts of population growth on these time series. Although in some instances such growth has been equated to the population growth of the geopolitical subdivisions containing the studied hospitals (Hay et al. 2002a) in the setting of our study this procedure is unreliable because of changes in geopolitical subdivisions of Kenya containing these hospitals, which increases the likelihood of heterogeneous trends in population growth because of differences in the counted populations (Lewontin and Levins, 1989). Also, this information is not a requisite for non-stationary time series analysis, especially when time series trends are the subject of study (Shumway and Stoffer, 2000).

In our analyses we used rainfall data from Kisumu as a proxy for rainfall in Maseno and Kendu Bay, given the close geographical proximity, $<35 \mathrm{~km}$, and similar altitude. DMI is an index for the IOD, defined as the difference in sea surface temperatures (SST) anomalies between western $\left(10^{\circ} \mathrm{S}-10^{\circ} \mathrm{N}, \quad 50^{\circ}-70^{\circ} \mathrm{E}\right)$ and eastern $\left(10^{\circ} \mathrm{S}-0^{\circ}\right.$, $90^{\circ}-110^{\circ} \mathrm{E}$ ) tropical Indian Ocean (Saji et al. 1999). The DMI data were obtained from Japan Agency for Marine-Earth Science and Technology, JAMSTEC, 
A

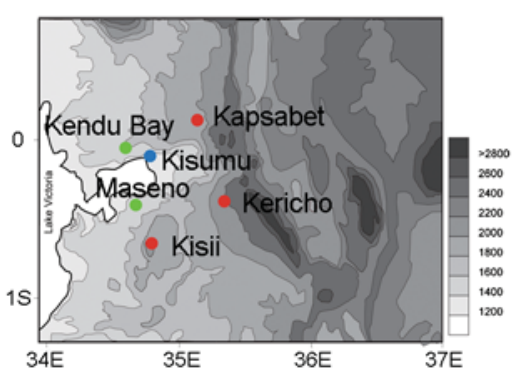

D

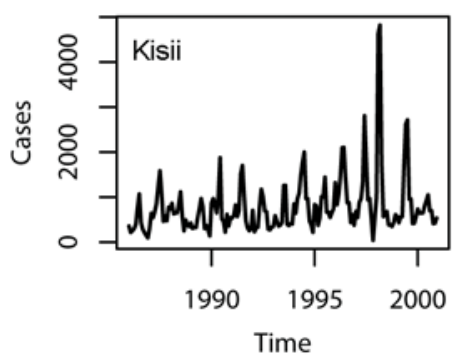

G

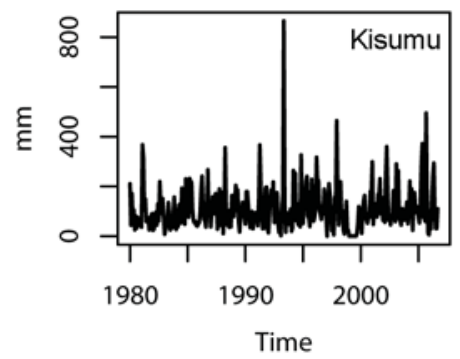

J

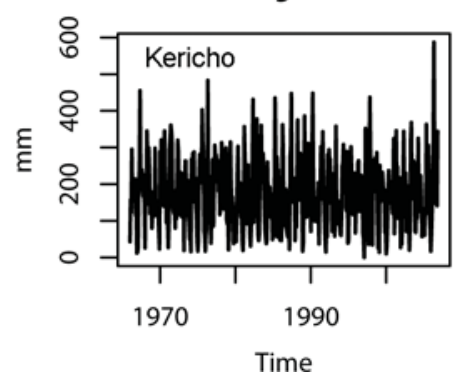

B

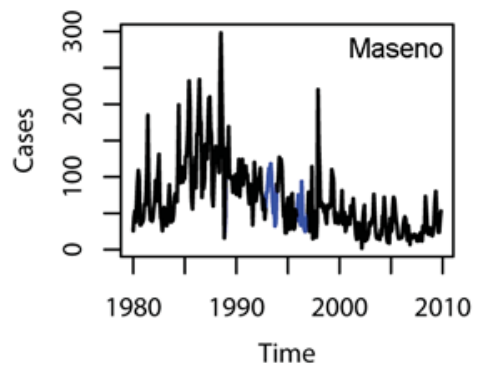

E

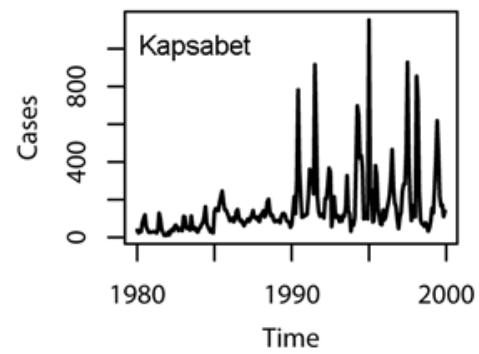

H

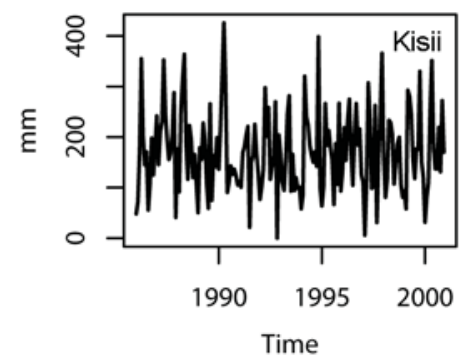

K

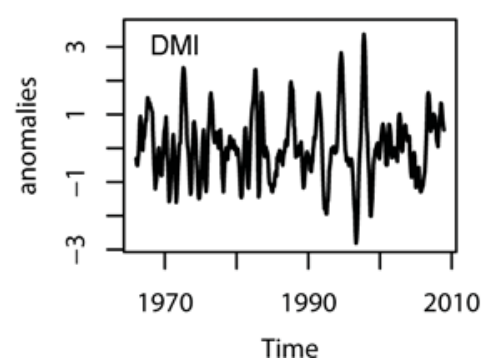

C

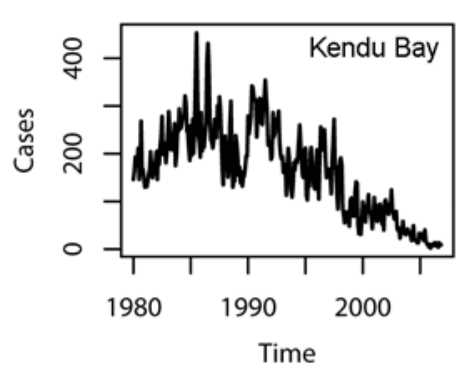

F

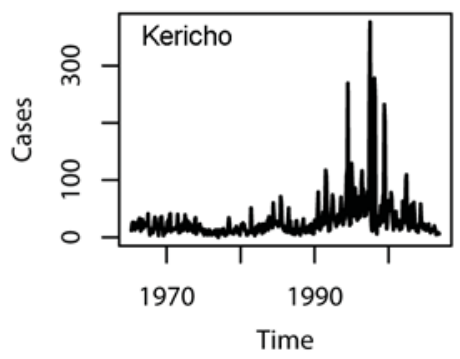

I

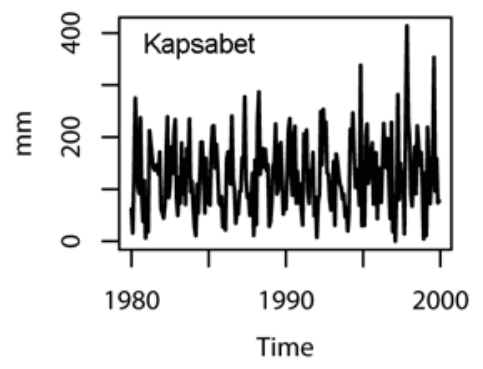

L

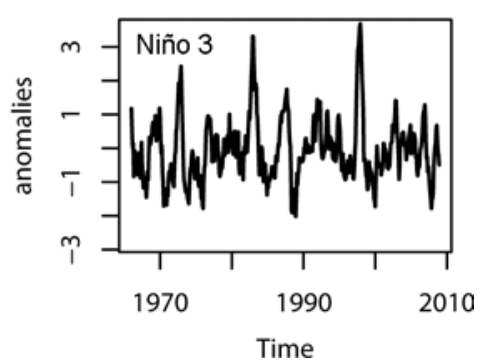

Fig. 1. Data. (A) Hospital locations. Clinical records of malaria infections for: (B) Maseno (May 1935, November 2009, $0^{\circ} 00^{\prime} 15^{\prime \prime} \mathrm{S}, 34^{\circ} 36^{\prime} 16^{\prime \prime} \mathrm{E}$, Altitude=1500 m); (C) Kendu Bay (January 1980, November 2006, 0²4'05"S, 34³9'56"E, Altitude $=1240 \mathrm{~m}$ ); (D) Kisii (January 1986, December 2000, 040'S, 3446'E, Altitude=1670 m); (E) Kapsabet

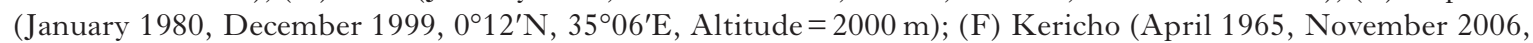
$0^{\circ} 23^{\prime} 55^{\prime \prime} \mathrm{N}, 35^{\circ} 15^{\prime} 30^{\prime \prime} \mathrm{E}$, Altitude $=2000 \mathrm{~m}$ ). Rainfall in: $(\mathrm{G})$ Kisumu (January 1980, December 2006, 06 $6^{\prime} \mathrm{S} 34^{\circ} 45^{\prime} \mathrm{E}$ Atltitude =1131 m); (H) Kisii (January, 1986, December 2000); (I) Kapsabet (January 1980, December 2000); (J) Kericho (January 1966, December 2006). (K) Dipole mode index (January 1966, December 2008) and (L) Niño 3 index (January 1966, December 2008). In panel (A), elevation is measured in meters, $\mathrm{m}$, and indicated by grey. Location color indicates the data available at each site; blue (rainfall); green (disease) and red (disease and rainfall). In panel (B) Blue indicates inputed values (see methods for details).

(www.jamstec.go.jp/frcgc/research/d1/iod/). The strength of the El Niño Southern Oscillation (ENSO) was measured by SST anomalies in El
Niño 3 area $\left(150^{\circ}-90^{\circ} \mathrm{W}, 5^{\circ} \mathrm{S}-5^{\circ} \mathrm{N}\right)$ of the Pacific Ocean, using data from the United States National Oceanic and Atmospheric Administration (NOAA) 
Climate Prediction Center (www.cpc.ncep.noaa. gov).

Time series analysis for breakpoints and regime shifts in the time domain

Exploratory analysis. To explore the dynamics of the time series, we performed an exploratory time series analysis, by examining the autocorrelation function of the malaria inpatient time series (Shumway and Stoffer, 2000). This inspection showed that most malaria time series $\left(y_{t}\right)$ were first order seasonal autoregressive processes where observations are correlated at both short (1 month) and seasonal time lags (12 months). Thus, we fitted the data to the following seasonal autoregressive null model:

$$
\begin{aligned}
y_{t}= & \mu+\phi_{1}\left(y_{t-1}-\mu\right)+\phi_{12}\left(y_{t-12}-\mu\right) \\
& +\phi_{1} \phi_{12}\left(y_{t-13}-\mu\right)+\alpha \text { Trend }+\varepsilon_{\mathrm{t}}
\end{aligned}
$$

For Kisii and Kericho, the time series were better described by a second order autoregressive process:

$$
y_{t}=\mu+\phi_{1}\left(y_{t-1}-\mu\right)+\phi_{2}\left(y_{t-2}-\mu\right)+\alpha \operatorname{Trend}+\varepsilon_{\mathrm{t}}
$$

In models (1) and (2) $\mu$ is the average value of the time series, Trend, a non-linear trend estimated with Loess, is included to account for the non-stationarity in the data which, in this case, is the changing mean through time (Chaves and Pascual, 2006). Loess is a non-parametric regression method based on the local fit of polynomials to data which get linked to obtain a smooth function which captures non-linear trends in time series data (Shumway and Stoffer, 2000). The error was assumed to be independent and normally distributed: $\varepsilon \sim N\left(0, \sigma^{2}\right)$. We used models (1) and (2) to pre-whiten the time series of the following climatic covariates: Rainfall, ENSO, and DMI. Prewhitening is a process that rules out spurious correlation between two time series, by removing (filtering) any common structure between the two studied time series (Chaves and Pascual, 2006). Residuals of the model presented in (1) and the prewhitened residuals of the climatic covariates were used to compute cross-correlation functions of the number of inpatients with each one of the climatic covariates.

Breakpoints and regime shifts. Data in Fig. 1 suggest the occurrence of secular changes in malaria incidence for the studied period. To test the significance of those apparent changes, and to determine the exact temporal localization of the changes (i.e., breakpoint, the time of an abrupt change indicating a regime shift) we used generalized fluctuation tests for the malaria incidence time series. This technique fits a parametric model to the data and derives an empirical fluctuation process (EFP). Briefly, an empirical fluctuation process depicts residual fluctuation from the studied data. This information can be used to detect unusual changes in, the variability or mean dynamics of, a time series by comparing the unexplained variability of the time series with the fluctuation of a Gaussian random process (Ploberger et al. 1989). We estimated EFPs that captured changes in the parameter estimates, where structural changes (i.e., regime shifts) in the time series under study can be observed in time (Ploberger et al. 1989; Chaves et al. 2008). We estimated the EFP using models that were selected in the absence of breakpoints. We also estimated an EFP for each rainfall time series to investigate possible impacts of regime shifts in covariates as cause of regime shifts in the malaria time series. We did not estimate EFPs for DMI and ENSO since it is well known that most of their variability is interannual (Saji et al. 1999; Saji and Yamagata, 2003).

Models to illustrate incidence changes associated with regime shifts. Based on the cross-correlation functions we built models with covariates at lags that had significant cross-correlations and considered the trends obtained with Loess. For the time series in which regime shifts were identified, we further estimated split trends by using the Loess method on the time series split at their breakpoints. We also fitted the best models that we obtained to the split series around the breakpoint. We studied changes on the magnitude of the climatic forcing by the covariates on the malaria time series by comparing the regression coefficients for the model fitted to the different segments of the split time series (Chaves et al. 2008). We selected the models using the Akaike Information Criterion (AIC), a metric that selects models based on the number of parameters and likelihood in order to avoid over-parameterized models (Shumway and Stoffer, 2000). Finally, in all cases, assumptions about model error were verified using standard procedures for time series analysis (Shumway and Stoffer, 2000).

\section{RESULTS}

All the time series that we studied had a marked seasonality, and their autocorrelation profiles correspond to those of seasonal autoregressive processes (Fig. 2A, E, I, M and Q). Also all the time series were significantly led (having significant cross-correlation at a positive lag) by rainfall (Fig. 2B, F, J, N and Q). With the exception of Maseno (Fig. 2C) and Kapsabet (Fig. 2O), all time series were significantly led by DMI, dipole mode index (Fig. $2 \mathrm{G}, \mathrm{K}, \mathrm{S}$ ). ENSO (E1 Niño 3) significantly led the malaria time series of Kisii (Fig. 2H) and Kericho (Fig. 2 T), but was uncorrelated with malaria dynamics at the other 3 locations (Fig. 2D, 2L, 2P). The regime shift analysis showed that the malaria time series for Maseno (Fig. 3A), Kisii (Fig. 3C) and Kericho (Fig. 3E) had breakpoints. In contrast Kendu Bay (Fig. 3B) and 

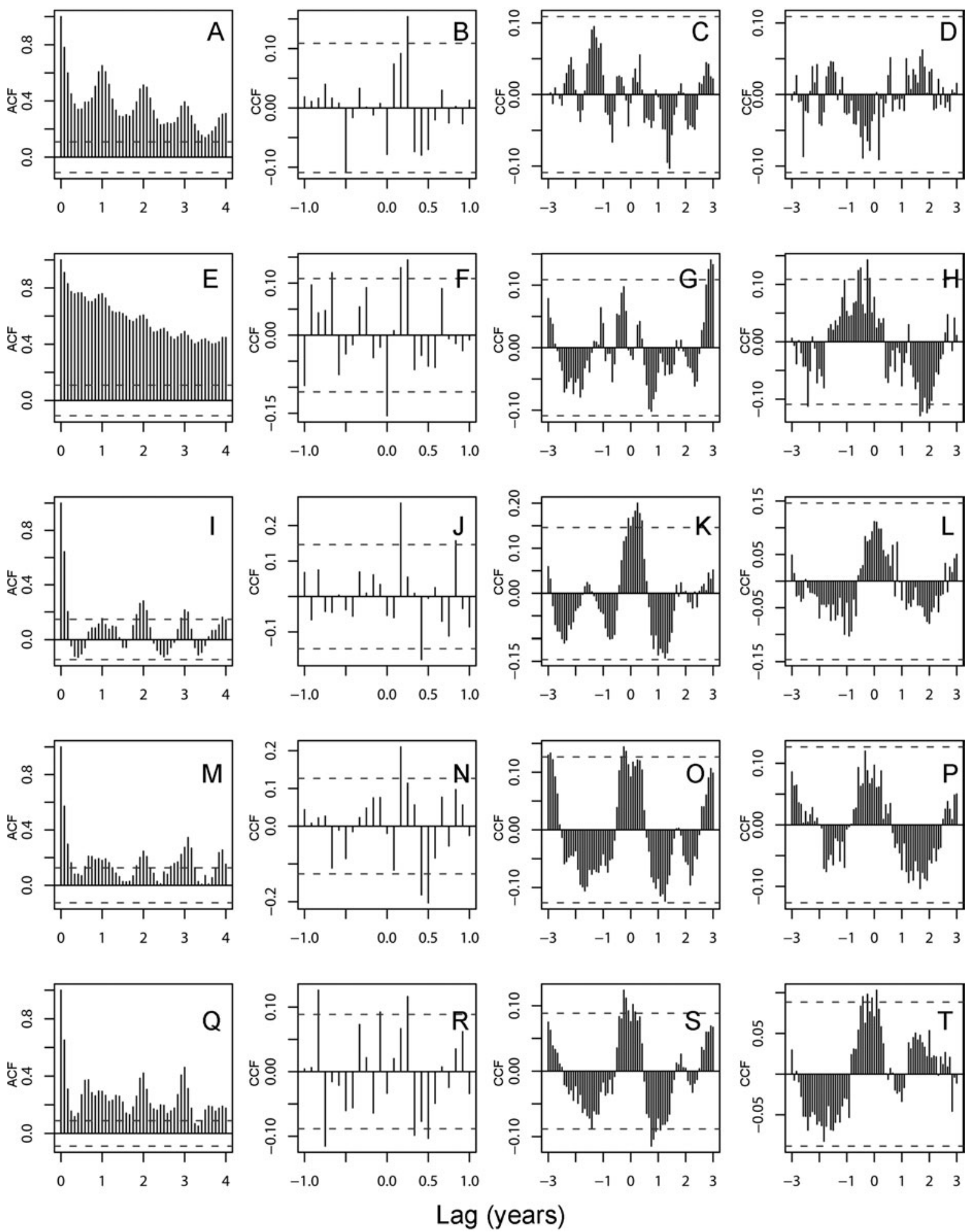

Fig. 2. Autocorrelation (ACF) and cross-correlation functions (CCF) (A) Maseno malaria ACF; (B) Maseno malaria and Kisumu rainfall CCF; (C) Maseno malaria and Dipole mode index, DMI, CCF; (D) Maseno malaria and the Niño 3 index, ENSO; (E) Kendu Bay malaria ACF; (F) Kendu Bay malaria and Kisumu rainfall CCF; (G) Kendu Bay malaria and DMI CCF; (H) Kendu Bay and ENSO CCF; (I) Kisii malaria ACF; (J) Kisii malaria and rainfall CCF; (K) Kisii malaria and DMI CCF; (L) Kisii malaria and ENSO CCC; (M) Kapsabet malaria ACF; (N) Kapsabet and rainfall CCF; (O) Kapsabet malaria and DMI CCF; (P) Kapsabet malaria and ENSO CCF; (Q) Kericho malaria ACF; (R) Kericho malaria and rainfall CCF; (S) Kericho malaria and DMI CCF; (T) Kericho malaria and ENSO CCF. In the $\mathrm{x}$ axis of all plots lag $=1$ means 12 months, dashed lines indicate the $95 \%$ confidence limits within which the ACFs and CCFs are not different from what is expected by random. 
A

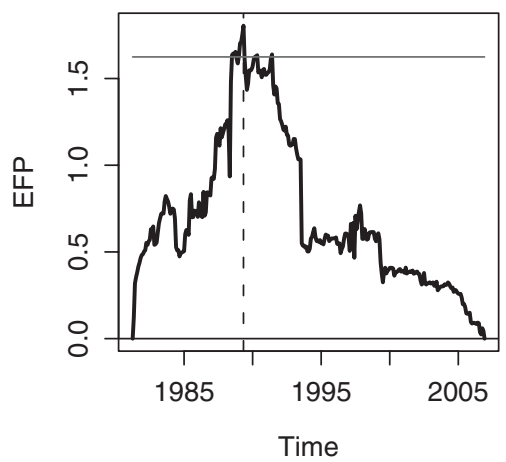

D

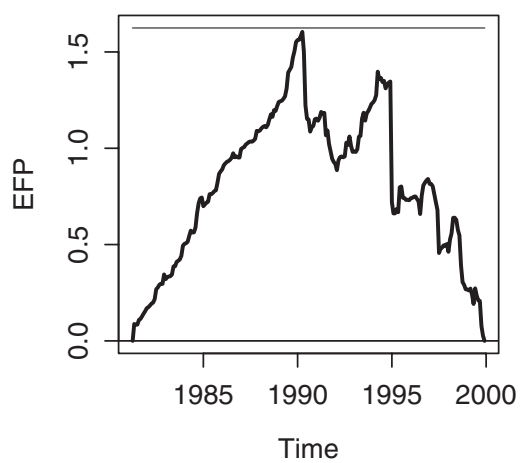

G

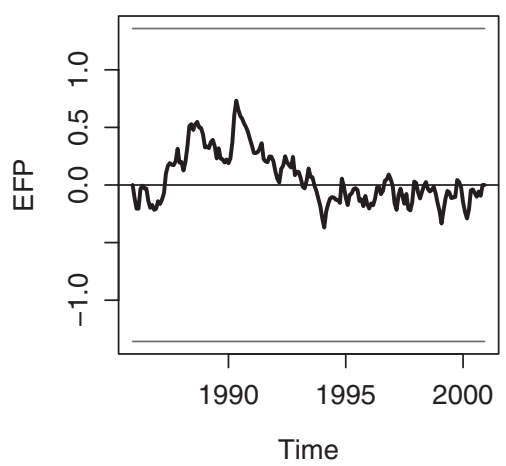

B

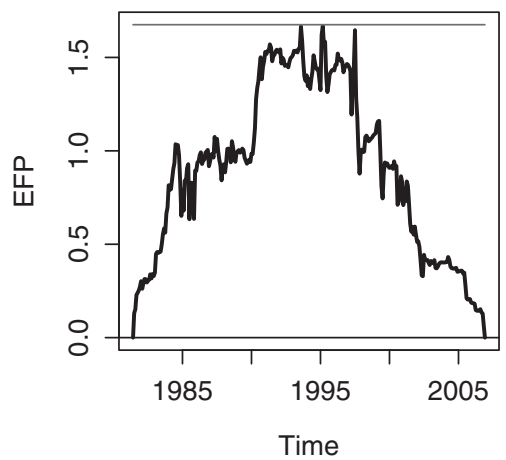

E

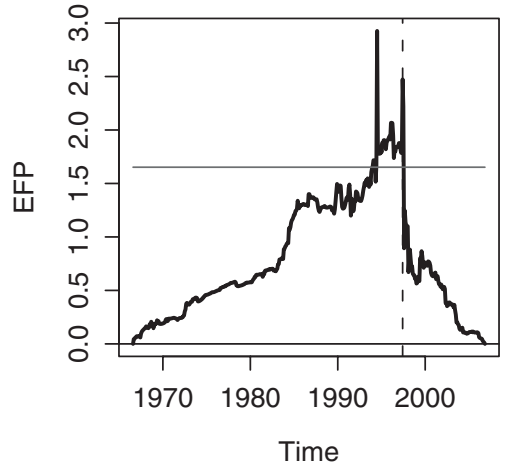

H

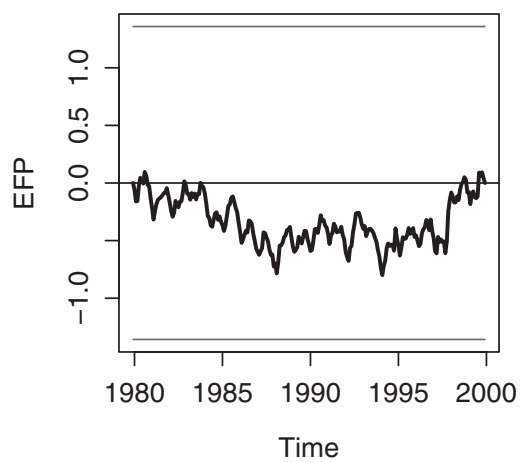

C

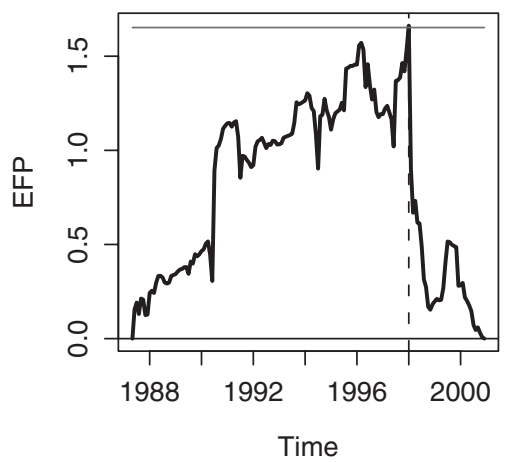

F

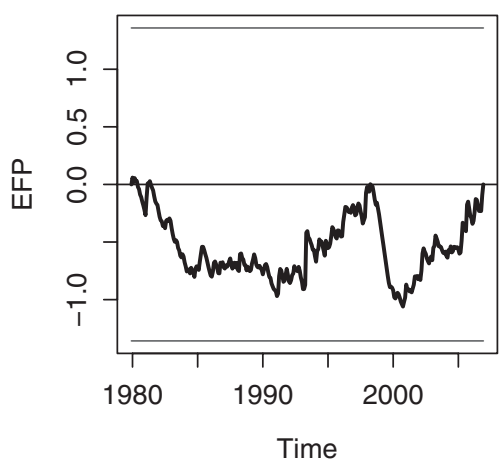

I

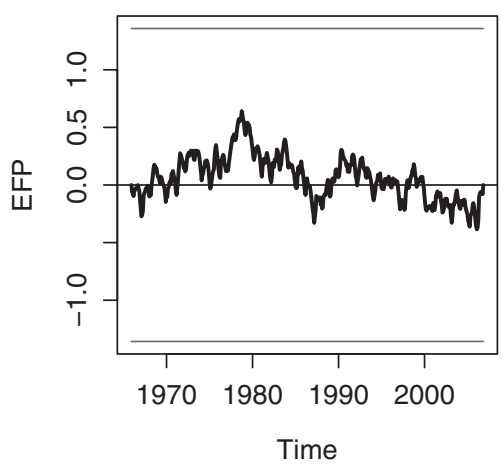

Fig. 3. Breakpoints for malaria incidence and rainfall time series. (A) Empirical fluctuation process, EFP, for Maseno malaria time series, as a seasonal autoregressive process with a non-linear trend, the dashed line indicates the most likely breakpoint, May 1989 ( $\mathrm{RE}=1 \cdot 80, P<0 \cdot 01)$; (B) EFP for Kendu Bay malaria time series as a seasonal autoregressive process with a non-linear trend, no indications of breakpoints $(\mathrm{RE}=1 \cdot 67, P>0 \cdot 05)$; (C) EFP for Kisii as a first order seasonal second order autoregressive process with a non-linear trend, the dashed line indicates the most likely breakpoint, January $1998(\mathrm{RE}=1 \cdot 66, P<0 \cdot 047)$; (D) EFP for Kapsabet, as a seasonal autoregressive process with a non-linear trend, no indications of breakpoints, $(\mathrm{RE}=1 \cdot 60, P>0 \cdot 05)$; (E) EFP for Kericho as a first order seasonal second-order autoregressive process with a non-linear trend, the dashed line indicates the most likely breakpoint, June 1997(RE $\left.=2 \cdot 93, P<10^{-7}\right)$; (F) Empirical fluctuation process, EFP, for Kisumu rainfall $(\mathrm{RE}=1 \cdot 06, P<0 \cdot 21)$; $(\mathrm{G}) \mathrm{EFP}$ Kisii rainfall $(\mathrm{RE}=0 \cdot 73, P<0 \cdot 66)$; $(\mathrm{H})$ EFP Kapsabet rainfall $(\mathrm{RE}=0 \cdot 80, P<0 \cdot 54)$; (I) EFP Kericho $(\mathrm{RE}=0 \cdot 64$, $P<0 \cdot 80)$. In all panels when values exceed the outer solid lines is an indication of a regime shift. In all panels the outer lines correspond to the extreme values expected if changes in the coefficients are driven by a random walk.

Kapsabet (Fig. 3D) had no breakpoints. None of the rainfall time series showed any breakpoints (Fig. $3 \mathrm{~F}$, G, H, I).

Seasonal autoregressive models confirmed the association between malaria incidence and rainfall observed in the cross-correlation analysis (Table 1). Figure 4 shows that for Maseno (Fig. 4A) and Kendu Bay (Fig. 4D) malaria incidence began a decreasing trend in the late 1980s. By contrast, in Kisii (Fig. 4B), Kericho (Fig. 4C) and Kapsabet (Fig. 4D) increasing 
Table 1. Model Selection

(Time series indicates the malaria time series, autoregressive components indicate the number of ordinary and seasonal autoregressive components respectively. Covariates indicate the different covariates with the respective lag, in months, within parenthesis: Trend is the non-linear trend obtained using loess, Rainfall, the local rainfall (in Maseno and Kendu Bay, rainfall from Kisumu was used as a proxy); ENSO, the Niño 3 index, and DMI, the dipole mode index. Breakpoint indicates whether a breakpoint was considered $(\mathrm{Y})$ or not $(\mathrm{N})$ and AIC indicates the Akaike Information criterion, highlighted values show the best models (minimum AIC).)

\begin{tabular}{|c|c|c|c|c|c|}
\hline $\begin{array}{l}\text { Time } \\
\text { Series }\end{array}$ & $\begin{array}{l}\text { Autoregressive } \\
\text { components }\end{array}$ & $\begin{array}{l}\text { Autoregressive } \\
\text { components } \\
\text { (Seasonal) }\end{array}$ & Covariates & Breakpoint & AIC \\
\hline \multirow[t]{6}{*}{ Maseno } & 1 & 1 & Trend & $\mathrm{N}$ & $3069 \cdot 2$ \\
\hline & 1 & 1 & Split Trend & $\mathrm{N}$ & $3056 \cdot 6$ \\
\hline & 1 & 1 & Trend, Rainfall(3) & $\mathrm{N}$ & $3063 \cdot 1$ \\
\hline & 1 & 1 & Split Trend, Rainfall(3) & $\mathrm{N}$ & $3050 \cdot 3$ \\
\hline & 1 & 1 & Trend, Rainfall(3) & $\mathrm{Y}$ & $3024 \cdot 4$ \\
\hline & 1 & 1 & Split Trend, Rainfall(3) & $\mathrm{Y}$ & $3018 \cdot 8$ \\
\hline \multirow[t]{3}{*}{ Kendu Bay } & 1 & 1 & Trend & $\mathrm{N}$ & $3226 \cdot 7$ \\
\hline & 1 & 1 & $\begin{array}{l}\text { Trend, Rainfall(0), Rainfall(3), ENSO(22), } \\
\operatorname{DMI}(35)\end{array}$ & $\mathrm{N}$ & $3213 \cdot 0$ \\
\hline & 1 & 1 & Trend, Rainfall(0), Rainfall(3), DMI(35) & $\mathrm{N}$ & $3211 \cdot 0$ \\
\hline \multirow[t]{7}{*}{ Kisii } & 2 & 1 & Trend & $\mathrm{N}$ & 2685 \\
\hline & 2 & 0 & Trend & $\mathrm{N}$ & 2685 \\
\hline & 2 & 0 & Split Trend & $\mathrm{N}$ & $2719 \cdot 4$ \\
\hline & 2 & 0 & Trend, Rainfall(2), DMI(2) & $\mathrm{N}$ & $2668 \cdot 4$ \\
\hline & 2 & 0 & Split Trend, Rainfall(2), DMI(2) & $\mathrm{N}$ & $2674 \cdot 8$ \\
\hline & 2 & 0 & Trend, Rainfall(2), DMI(2) & $\mathrm{Y}$ & $2613 \cdot 5$ \\
\hline & 2 & 0 & Split Trend, Rainfall(2), DMI(2) & $\mathrm{Y}$ & $2613 \cdot 5$ \\
\hline \multirow[t]{3}{*}{ Kapsabet } & 1 & 1 & Trend & $\mathrm{N}$ & $2963 \cdot 1$ \\
\hline & 1 & 0 & Trend & $\mathrm{N}$ & $2961 \cdot 1$ \\
\hline & 1 & 0 & Trend, Rainfall(2), Rainfall(6) & $\mathrm{N}$ & $2943 \cdot 7$ \\
\hline \multirow[t]{9}{*}{ Kericho } & 2 & 1 & Trend & $\mathrm{N}$ & $4551 \cdot 1$ \\
\hline & 2 & 0 & Trend & $\mathrm{N}$ & $4549 \cdot 4$ \\
\hline & 2 & 0 & Split Trend & $\mathrm{N}$ & $4538 \cdot 7$ \\
\hline & 2 & 0 & Trend, Rainfall(3), ENSO(2), DMI(1) & $\mathrm{N}$ & $4543 \cdot 2$ \\
\hline & 2 & 0 & Split Trend, Rainfall(3), ENSO(2), DMI(1) & $\mathrm{N}$ & $4511 \cdot 5$ \\
\hline & 2 & 0 & Trend, Rainfall(3), DMI(1) & $\mathrm{N}$ & $4542 \cdot 33$ \\
\hline & 2 & 0 & Split Trend, Rainfall(3), DMI(1) & $\mathrm{N}$ & $4509 \cdot 55$ \\
\hline & 2 & 0 & Trend, Rainfall(3), DMI(1) & $\mathrm{Y}$ & $4482 \cdot 88$ \\
\hline & 2 & 0 & Split Trend, Rainfall(3), DMI(1) & $\mathrm{Y}$ & $4432 \cdot 4$ \\
\hline
\end{tabular}

trends in malaria transmission were observed in the mid and late 1990s and these trends began to decrease in the early 2000s (Fig. 4B, C and D). In general, split trends showed similar patterns to contiguous trends (Fig. 4A, B, C). However, it is important to note that in Kisii, the second half of the split trend gave too much importance to a few observations (Fig. 4B). In all the best models (Table 1) normality and homokedasticity tests confirmed that the error was normal, independent and identically distributed, thus confirming the validity of our analyses.

Regarding the influence of climatic covariates, with the exception of Kendu Bay and Kapsabet where rainfall had both positive and negative impacts on malaria incidence, rainfall significantly increased monthly malaria incidence (Table 2). The process of model selection showed that for those time series that were associated with both El Niño 3 and DMI, the latter was the best predictor (Table 1). Increases in DMI were positively associated with increases in malaria incidence. In Maseno and Kericho the inclusion of the breakpoints and splits trends maximized the likelihood of the models (Table 1). In Kisii only the inclusion of the breakpoint improved model fit (Table 1), probably because of the irregular second half of the split time series (Fig. 4B). Finally, Maseno and Kericho show opposits patterns regarding the variability associated with their regime shifts. In Maseno, the variability measured model standard deviation ( $\hat{\sigma}$, Table 2 ) decreased after the breakpoint, while in Kisii and Kericho it increased.

\section{DISCUSSION}

The possible association between changes in highland malaria transmission patterns and global warming has motivated a heated debate (Chaves and Koenraadt, 2010). From positions that claim to have explained malaria trends as a direct product of temperature trends (Alonso et al. 2011) to positions that neglect the known impacts that changing 
A

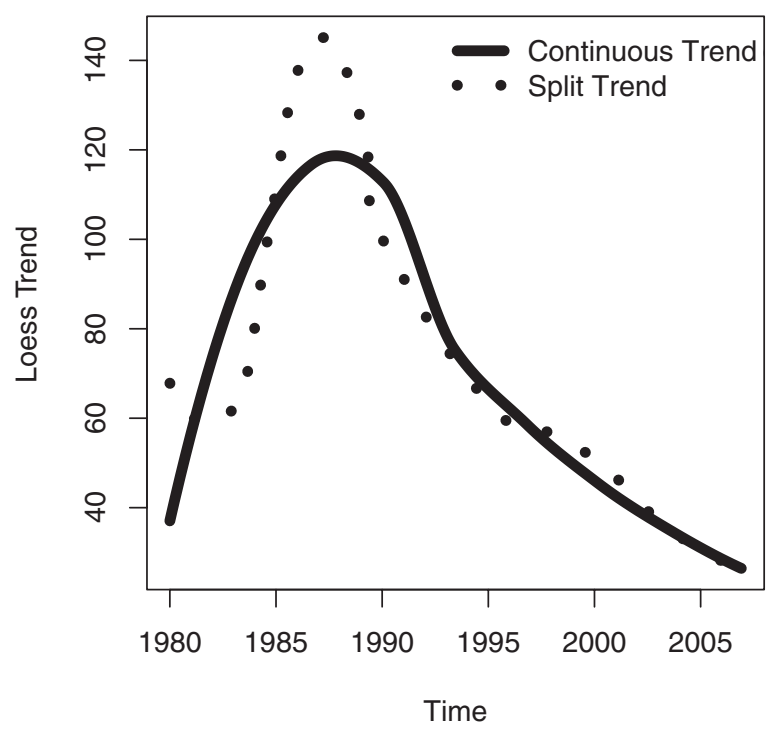

C

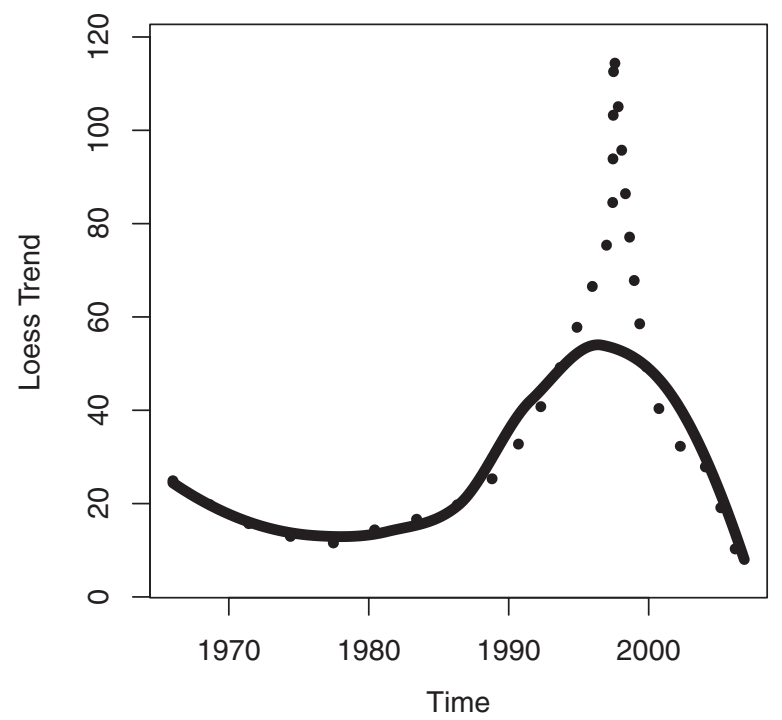

B

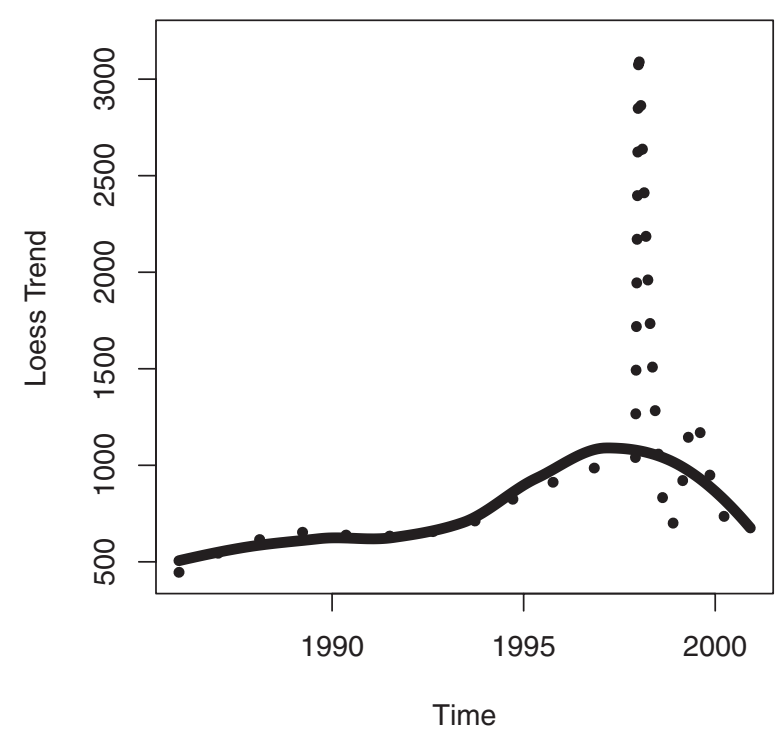

D

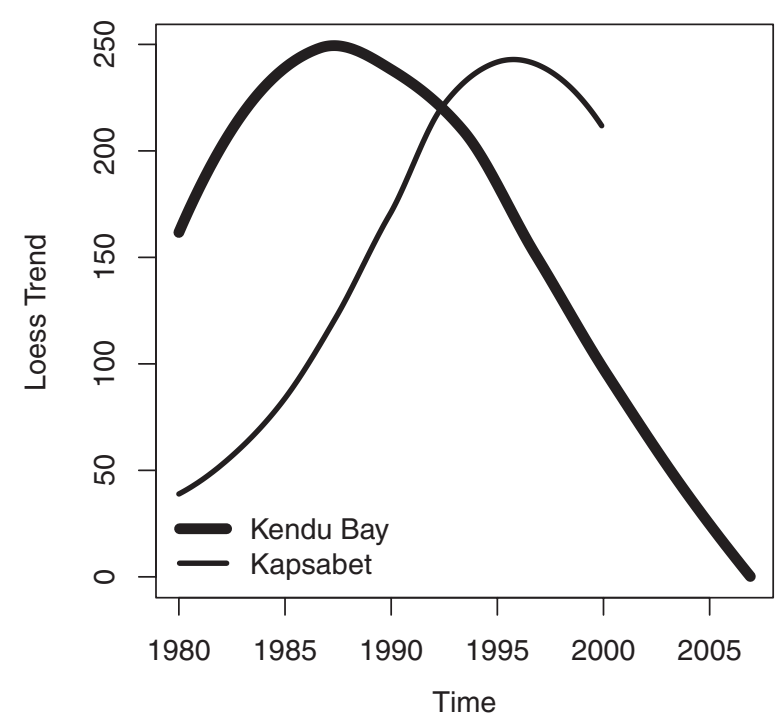

Fig. 4. Malaria trends obtained with Loess. (A) Maseno (B) Kissi (C) Kericho (D) Kendu Bay and Kapsabet. In all panels continuous lines indicate continuous trends. In panels (A), (B) and (C), the dotted lines indicate split trends.

environments have on organisms (Reiter, 2008), efforts to understand the linkages between malaria transmission and climate change have lacked robustness in the validation of inferences with independent observations (Levins, 2006). This is illustrated by the many studies that have exclusively focused on Kericho (Hay et al. 2000; Shanks et al. 2005; Pascual et al. 2008; Artzy-Randrup et al. 2010; Childs and Boots, 2010; Alonso et al. 2011).

Here, we have taken a different approach and studied 5 time series from Lake Victoria basin, an area with common regional rainfall patterns (Anyah and Semazzi, 2004; Anyah et al. 2006) and a homogeneous signature of global climatic phenomena like the IOD (Saji et al. 1999; Saji and Yamagata, 2003). With the 5 time series we attempted to characterize patterns of malaria incidence. However, extending the analysis to 5 sites had the cost of uncertainty about homogeneity in data quality, especially when compared with Kericho, which is assumed to have less uncertainty in the parasitological confirmation of cases (Hay et al. 2000, 2002a; Shanks et al. 2000, 2002, 2005). Nevertheless, we consider the data are comparable because of their common attributes: (i) all time series only consider the most severe (or virulent in a wider biological sense) malaria cases, those requiring admission to the hospital (inpatient data); (ii) in all cases the first line of diagnosis was merely clinical (passive detection); (iii) malaria is the most likely disease to produce morbidity with severe malaria symptoms in the area (Menge et al. 2008; Feikin et al. 2010); (iv) there were 
Table 2. Parameter estimates

(Time series indicates the malaria time series. Parameter indicates the predictor for which the parameter was estimated: Mean is the mean value of the series, AR and SAR are, respectively, ordinary and seasonal autoregressive predictors, Trend is the non-linear trend obtained with loess, Rainfall is the local rainfall (Kisumu rainfall for Maseno and Kendu Bay). The value inside the parenthesis indicates the lag of the covariates (in months). No shift presents estimates for models without breakpoints. Before and After present, respectively, estimates before and after the breakpoints. $P(<0 \cdot 05)$ indicates the significance of each parameter in the models N (no shift)/ B (before breakpoint)/ A (after breakpoint).)

\begin{tabular}{|c|c|c|c|c|c|c|}
\hline \multirow{2}{*}{$\frac{\text { Time Series }}{\text { Maseno }}$} & \multicolumn{2}{|c|}{ Parameter (Lag) } & \multirow{2}{*}{$\begin{array}{l}\text { No Shift } \\
71.95 \pm 3.97\end{array}$} & \multirow{2}{*}{$\frac{\text { Before }}{74 \cdot 80 \pm 11 \cdot 43}$} & \multirow{2}{*}{$\frac{\text { After }}{72 \cdot 14 \pm 4 \cdot 06}$} & \multirow{2}{*}{$\frac{P(<0.05)}{\mathrm{N} / \mathrm{B} / \mathrm{A}}$} \\
\hline & $\hat{\mu}$ & Mean(-) & & & & \\
\hline & $\phi_{1}$ & $\operatorname{AR}(1)$ & $0 \cdot 51 \pm 0.05$ & $0.53 \pm 0.09$ & $0 \cdot 44 \pm 0 \cdot 06$ & $\mathrm{~N} / \mathrm{B} / \mathrm{A}$ \\
\hline & $\phi_{12}$ & $\operatorname{SAR}(12)$ & $0 \cdot 27 \pm 0 \cdot 05$ & $0 \cdot 36 \pm 0 \cdot 11$ & $0 \cdot 25 \pm 0 \cdot 06$ & $\mathrm{~N} / \mathrm{B} / \mathrm{A}$ \\
\hline & $\hat{\alpha}$ & Split Trend(-) & $1 \cdot 03 \pm 0 \cdot 11$ & $0.99 \pm 0 \cdot 25$ & $1 \cdot 03 \pm 0 \cdot 15$ & $\mathrm{~N} / \mathrm{B} / \mathrm{A}$ \\
\hline & $\hat{\beta}$ & Rainfall(3) & $0 \cdot 046 \pm 0 \cdot 016$ & $0 \cdot 13 \pm 0 \cdot 04$ & $0 \cdot 019 \pm 0 \cdot 015$ & $\mathrm{~N} / \mathrm{B}$ \\
\hline & $\hat{\sigma}$ & - & $26 \cdot 25$ & $31 \cdot 41$ & $21 \cdot 43$ & - \\
\hline \multirow[t]{8}{*}{ Kendu Bay } & $\hat{\mu}$ & Mean(-) & $167 \cdot 75 \pm 6 \cdot 83$ & - & - & $\mathrm{N}$ \\
\hline & $\phi_{1}$ & $\operatorname{AR}(1)$ & $0 \cdot 64 \pm 0 \cdot 04$ & - & - & $\mathrm{N}$ \\
\hline & $\phi_{12}$ & $\operatorname{SAR}(12)$ & $0 \cdot 21 \pm 0 \cdot 06$ & - & - & $\mathrm{N}$ \\
\hline & $\hat{\alpha}$ & Trend(-) & $1 \cdot 02 \pm 0.08$ & - & - & $\mathrm{N}$ \\
\hline & $\hat{\beta}_{1}$ & Rainfall(0) & $-0 \cdot 048 \pm 0 \cdot 020$ & - & - & $\mathrm{N}$ \\
\hline & $\hat{\beta}_{2}$ & Rainfall(3) & $0 \cdot 045 \pm 0 \cdot 020$ & - & - & $\mathrm{N}$ \\
\hline & $\hat{\gamma}^{2}$ & $\operatorname{DMI}(35)$ & $11 \cdot 51 \pm 3 \cdot 95$ & - & - & $\mathrm{N}$ \\
\hline & $\hat{\sigma}$ & - & $33 \cdot 45$ & - & - & - \\
\hline \multirow[t]{7}{*}{ Kisii* } & $\hat{\mu}$ & Mean(-) & $787 \cdot 19 \pm 53 \cdot 64$ & $763 \cdot 37 \pm 57 \cdot 39$ & $569 \cdot 57 \pm 210 \cdot 13$ & $\mathrm{~N} / \mathrm{B} / \mathrm{A}$ \\
\hline & $\phi_{1}$ & $\operatorname{AR}(1)$ & $0 \cdot 77 \pm 0 \cdot 07$ & $0 \cdot 60 \pm 0 \cdot 10$ & $0 \cdot 82 \pm 0 \cdot 16$ & $\mathrm{~N} / \mathrm{B} / \mathrm{A}$ \\
\hline & $\phi_{12}$ & $\operatorname{AR}(2)$ & $-0 \cdot 36 \pm 0.07$ & $-0 \cdot 06 \pm 0 \cdot 10$ & $-0 \cdot 47 \pm 0 \cdot 19$ & $\mathrm{~N} / \mathrm{A}$ \\
\hline & $\hat{\alpha}$ & Trend(-) & $1 \cdot 16 \pm 0 \cdot 28$ & $0 \cdot 86 \pm 0 \cdot 30$ & $3 \cdot 28 \pm 1 \cdot 14$ & $\mathrm{~N} / \mathrm{B} / \mathrm{A}$ \\
\hline & $\hat{\beta}$ & Rainfall(2) & $1 \cdot 47 \pm 0 \cdot 37$ & $1 \cdot 69 \pm 0 \cdot 37$ & $0 \cdot 79 \pm 1 \cdot 20$ & $\mathrm{~N} / \mathrm{B}$ \\
\hline & $\hat{\gamma}$ & $\operatorname{DMI}(2)$ & $117 \cdot 17 \pm 47 \cdot 88$ & $8 \cdot 08 \pm 44 \cdot 82$ & $657 \cdot 33 \pm 159 \cdot 19$ & $\mathrm{~N} / \mathrm{A}$ \\
\hline & $\hat{\sigma}$ & - & $417 \cdot 95$ & $313 \cdot 29$ & $502 \cdot 6$ & - \\
\hline \multirow[t]{6}{*}{ Kapsabet } & $\hat{\mu}$ & Mean(-) & $158 \cdot 86 \pm 26 \cdot 18$ & - & - & $\mathrm{N}$ \\
\hline & $\phi_{1}$ & $\mathrm{AR}(1)$ & $0 \cdot 43 \pm 0 \cdot 06$ & - & - & $\mathrm{N}$ \\
\hline & $\hat{\alpha}$ & Trend(-) & $0 \cdot 99 \pm 0 \cdot 20$ & - & - & $\mathrm{N}$ \\
\hline & $\hat{\beta}_{1}$ & Rainfall(2) & $0 \cdot 38 \pm 0 \cdot 12$ & - & - & $\mathrm{N}$ \\
\hline & $\hat{\beta}_{2}$ & Rainfall(6) & $-0 \cdot 40 \pm 0 \cdot 12$ & - & - & $\mathrm{N}$ \\
\hline & $\hat{\sigma}$ & - & $127 \cdot 10$ & - & - & - \\
\hline \multirow[t]{7}{*}{ Kericho } & $\hat{\mu}$ & Mean(-) & $28 \cdot 63 \pm 1 \cdot 66$ & $31 \cdot 70 \pm 2 \cdot 49$ & $29 \cdot 68 \pm 5 \cdot 13$ & $\mathrm{~N} / \mathrm{B} / \mathrm{A}$ \\
\hline & $\phi_{1}$ & $\mathrm{AR}(1)$ & $0 \cdot 66 \pm 0 \cdot 04$ & $0.67 \pm 0.06$ & $0 \cdot 85 \pm 0 \cdot 08$ & $\mathrm{~N} / \mathrm{B} / \mathrm{A}$ \\
\hline & $\phi_{2}$ & $\operatorname{AR}(2)$ & $-0 \cdot 32 \pm 0.04$ & $-0 \cdot 10 \pm 0 \cdot 07$ & $-0.46 \pm 0.09$ & $\mathrm{~N} / \mathrm{A}$ \\
\hline & $\hat{\alpha}$ & Split Trend(-) & $1 \cdot 01 \pm 0.08$ & $1 \cdot 47 \pm 0 \cdot 16$ & $0 \cdot 71 \pm 0 \cdot 19$ & $\mathrm{~N} / \mathrm{B} / \mathrm{A}$ \\
\hline & $\hat{\beta}$ & Rainfall (3) & $0 \cdot 026 \pm 0 \cdot 012$ & $0 \cdot 025 \pm 0 \cdot 012$ & $0 \cdot 024 \pm 0 \cdot 028$ & $\mathrm{~N} / \mathrm{B}$ \\
\hline & $\hat{\gamma}$ & $\operatorname{DMI}(1)$ & $3 \cdot 26 \pm 1 \cdot 76$ & $5 \cdot 77 \pm 2 \cdot 25$ & $4 \cdot 20 \pm 5 \cdot 55$ & $\mathrm{~B}$ \\
\hline & $\hat{\sigma}$ & - & $24 \cdot 20$ & $20 \cdot 12$ & $29 \cdot 86$ & - \\
\hline
\end{tabular}

* These are the parameters for the model with a contiguous trend (see Table 1 and Results).

no systematic changes in the implementation of malaria confirmation i.e., we have no reason to suspect any seasonal, or secular, change in diagnostic criteria at each site. Obviously, these biases on the data limits the inferences to severe cases, which most likely underestimate disease transmission as shown by highly standardized blood-slide examination (Molineaux et al. 1980) and molecular diagnostic techniques (Ofulla et al. 2005; Menge et al. 2008), not to mention the likelihood of inaccuracy that could emerge from stressed staff dealing with epidemics at resource limited health facilities. However, since the type of cases studied over time were homogeneous, there is no threat to comparison validity over time, because the data fits the standards for a sound analysis of trends (Shumway and Stoffer, 2000).
Our results show that malaria incidence in Lake Victoria basin displayed trends that are similar over given altitudinal ranges. At altitudes below $1600 \mathrm{~m}$, we found that malaria trends began to decrease in the late 1980s. In contrast, at higher altitudes, above $1600 \mathrm{~m}$, we found that malaria increased in the mid and late 1990s, confirming a pattern noticed in East Africa that linked unexpectedly high levels of malaria transmission associated with IOD and ENSO (Hashizume et al. 2009; Lindblade et al. 1999, 2001; Zhou et al. 2004). In this context, population growth is indirectly associated with malaria emergence in the African highlands because of its impact on land use change, and subsequent changes in the ecology of living organisms involved in malaria transmission (Lindblade et al. 2000). Montane 
rainforests used to cover the highlands surrounding Lake Victoria, while the lowlands in the lake basin were less forested. Now the highland forests have mostly disappeared, and locals are still clearing the last patches of forest that remained in the valley bottoms (Verschuren et al. 2002), mainly for the purposes of self-subsistence agriculture (Ernst et al. 2009). In addition, population growth in this region, with a long history of unequal access to land derived from colonial plundering (Prothero, 1965; Chaves and Koenraadt, 2010), also forces locals to migrate to valley bottoms where they are likely exposed to a large number of vectors and high malaria transmission (Munyekenye et al. 2005). Thus, the indirect impacts of population growth, which are ultimately expressed in diverse degrees of land transformation and human movement, make our analysis robust to the lack of explicit consideration of population growth data. Moreover, regulation of malaria transmission, which is best described by frequency dependent models (Hay et al. 2000; Pascual et al. 2008; Chaves et al. 2009; Alonso et al. 2011), implies that population growth plays a relatively minor role on the dynamics of transmission (McCallum et al. 2001). In fact, several studies have shown that there is not a direct mapping between population growth and trends in malaria transmission, both in this area (Hay et al. 2002a,b; Pascual et al. 2008; Alonso et al. 2011) and outside Africa (Chaves et al. 2009). On the other hand, frequency dependent transmission models are sensitive to conditions of population immunity, which is indeed reduced in highland populations, when compared to lowland populations (John et al. 2002), as product of a decreased exposure to malaria infection (Drakeley et al. 2005).

The late 1990s malaria epidemics in lake Victoria basin, above $1600 \mathrm{~m}$, were so large that they significantly increased the variance of the time series; probably explaining the occurrence of breakpoints in Kisii and Kericho in 1997/1998. One hypothesis that could explain the synchrony in the breakpoints, which requires further testing in the field, is the synchronization of mosquito populations and subsequent malaria transmission triggered by rainfall. Previous studies have shown that catching adult Anopheles gambiae mosquitoes, the main malaria vector in East Africa highlands, is extremely difficult (Koenraadt et al. 2006). Even so, vector densities have been shown to significantly increase following rainfall (Minakawa et al. 2002, 2005b, 2006), even if prolonged rainfall can wash away mosquito larvae (Paaijmans et al. 2007). Occasional floods and rainfall runoff create numerous stagnant water pools in valley bottoms that are poorly drained. If riparian forests are cleared, these stagnant water pools become suitable breeding sites for major malaria vectors that mainly inhabit small sun-lit water pools, $A n$. gambiae and An. arabiensis (Gimnig et al. 2001;
Minakawa et al. 2005a). Besides its direct impact on mosquito density, rainfall also determines a series of wetness indices that are major risk factors for malaria infection in western Kenya (Cohen et al. 2010), probably by enhancing mosquito movement across the landscape, a pattern common among several mosquito genera, including Anopheles (Silver, 2008). Thus, to explain the heterogeneity in malaria transmission trends, we consider that finely grained landscape transformation, in synergy with increased rainfall associated with IOD (Hashizume et al. 2009), probably were major drivers of the large epidemics above $1600 \mathrm{~m}$.

Regarding the decreasing malaria trends, the mechanism driving changes at low and high altitudes seems to be different. At low altitude, below $1600 \mathrm{~m}$, malaria trends began to decrease before the 1990s, and could likely reflect self-regulation of transmission, either by immunity development (Hay et al. 2000; Pascual et al. 2008), or the more general reduced inflow of susceptible individuals, i.e., immune adults and well protected children, as observed outside Africa (Chaves et al. 2008, 2009, 2011; Kaneko et al. 1998, 2000). At high altitude $(>1600 \mathrm{~m})$, large-scale malaria control interventions with insecticide treated bednets could have driven both the reduction of malaria transmission and mosquito population size (Lindblade et al. 2004) and a shift of dominant vector species, from $A n$. gambiae to An. arabiensis (Bayoh et al. 2010). In fact, the interruption of malaria transmission has been documented in highland sites near the locations we studied (John et al. 2009; Zhou et al. 2011). More, generally differences in malaria incidence trends can reflect a myriad of historic changes in East Africa. From demographic changes to land use changes (Lindblade et al. 2000; Lindsay and Martens, 1998), drug resistance (Shanks et al. 2005), and global warming (Alonso et al. 2011) differences in malaria trends ultimately link the sensitivity of malaria transmission to its context (Chaves and Koenraadt, 2010). Finally, the scarcity of contextual information and long-term malaria records necessary to robustly determine the drivers behind malaria transmission trends highlight the need for surveillance and for climatic and demographic systems able to record high quality data. These data are necessary to understand heterogeneities in malaria transmission across spatial scales and to make sound inferences about the impacts of climate change and control/elimination interventions on malaria transmission.

\section{ACKNOWLEDGEMENTS}

We thank R. Snow for providing hospital and meteorological data for Kericho. We also thank the staff at the Kendu Bay, Maseno, Kisii and Kapsabet hospitals for their help with data compilation. 


\section{F I NANCIAL SUPPORT}

This study was supported by a Nagasaki University Institute of Tropical Medicine cooperative grant and Japan Society for the Promotion of Science.

\section{REFERENCES}

Abeku, T. A., De Vlas, S. J., Borsboom, G., Tadege, A., Gebreyesus, Y., Gebreyohannes, H., Alamirew, D., Seifu, A., Nagelkerke, N. J. D. and Habbema, J. D. F. (2004). Effects of meteorological factors on epidemic malaria in Ethiopia: a statistical modelling approach based on theoretical reasoning. Parasitology 128, 585-593. doi: 10.1017/ s003182004005013.

Alonso, D., Bouma, M. J. and Pascual, M. (2011). Epidemic malaria and warmer temperatures in recent decades in an East African highland. Proceedings of the Royal Society of London, B 278, 1661-1669. doi: 10.1098/ rspb.2010.2020.

Anyah, R. and Semazzi, F. (2004). Simulation of the sensitivity of Lake Victoria basin climate to lake surface temperatures. Theoretical and Applied Climatology 79, 55-69.

Anyah, R., Semazzi, F. and Xie, L. (2006). Simulated physical mechanisms associated with multi-scale climate variability over Lake Victoria Basin in East Africa. Monthly Weather Review 134, 3588-3609. Artzy-Randrup, Y., Alonso, D. and Pascual, M. (2010). Transmission intensity and drug resistance in malaria population dynamics: Implications for Climate Change. PLoS ONE 5, e13588. doi: 10.1371/journal pone. 0013588 .

Bayoh, M. N., Mathias, D. K., Odiere, M.R., Mutuku, F. M., Kamau, L., Gimnig, J. E., Vulule, J. M., Hawley, W. A. Hamel, M. J. and Walker, E. D. (2010). Anopheles gambiae: historical population decline associated with regional distribution of insecticidetreated bed nets in western Nyanza Province, Kenya. Malaria fournal 9, 62. doi: 10.1186/1475-2875-9-62.

Bødker, R., Akida, J., Shayo, D., Kisinza, W., Msangeni, H. A. Pedersen, E. M. and Lindsay, S. W. (2003). Relationship between altitude and intensity of malaria transmission in the Usambara Mountains, Tanzania. Fournal of Medical Entomology 40, 706-717.

Bødker, R., Msangeni, H. A., Kisinza, W. and Lindsay, S. W. (2006) Relationship between the intensity of exposure to malaria parasites and infection in the Usambara Mountains, Tanzania. American Fournal of Tropical Medicine and Hygiene 74, 716-723.

Chaves, L. F., Kaneko, A. and Pascual, M. (2009). Random, top-down, or bottom-up coexistence of parasites: malaria population dynamics in multi-parasitic settings. Ecology 90, 2414-2425.

Chaves, L. F., Kaneko, A., Taleo, G., Pascual, M. and Wilson, M. L (2008). Malaria transmission pattern resilience to climatic variability is mediated by insecticide-treated nets. Malaria fournal 7, 100 .

Chaves, L.F. and Koenraadt, C. J. M. (2010). Climate change and highland malaria: fresh air for a hot debate. The Quarterly Review of Biology 85, 27-55

Chaves, L. F. and Pascual, M. (2006). Climate cycles and forecasts of cutaneous leishmaniasis, a nonstationary vector-borne disease. Plos Medicine 3, 1320-1328. doi: e29510.1371/journal.pmed.0030295.

Chaves, L.F., Taleo, G., Kalkoa, M. and Kaneko, A. (2011) Spleen rates in children: an old and new surveillance tool for malaria elimination initiatives in island settings. Transactions of the Royal Society of Tropical Medicine and Hygiene 105, 226-231. doi: 10.1016/j. trstmh.2011.01.001.

Childs, D. Z. and Boots, M. (2010). The interaction of seasonal forcing and immunity and the resonance dynamics of malaria. Fournal of the Royal Society Interface 7, 309-319. doi: 10.1098/rsif.2009.0178.

Cohen, J. M., Ernst, K. C., Lindblade, K. A., Vulule, J. M., John, C. C. and Wilson, M. L. (2010). Local topographic wetness indices predict household malaria risk better than land-use and land-cover in the western Kenya highlands. Malaria Fournal 9, 328. doi: 10.1186/1475-2875-9-328. Drakeley, C. J., Carneiro, I., Reyburn, H., Malima, R., Lusingu, J.P. A., Cox, J., Theander, T. G., Nkya, W. M. M. M., Lemnge, M. M. and Riley, E. M. (2005). Altitude-dependent and -independent variations in Plasmodium falciparum prevalence in Northeastern Tanzania. Fournal of Infectious Diseases 191, 1589-1598. doi: 10.1086/429669.

Ernst, K. C., Lindblade, K. A., Koech, D., Sumba, P. O. Kuwuor, D. O., John, C. C. and Wilson, M. L. (2009). Environmental, socio-demographic and behavioural determinants of malaria risk in the western Kenyan highlands: a case-control study. Tropical Medicine
छ International Health 14, 1258-1265. doi: 10.1111/j.1365-3156. 2009.02370.x.

Feikin, D. R., Audi, A., Olack, B., Bigogo, G. M., Polyak, C., Burke, H. Williamson, J. and Breiman, R.F. (2010). Evaluation of the optima recall period for disease symptoms in home-based morbidity surveillance in rural and urban Kenya. International Fournal of Epidemiology 39, 450-458. doi: 10.1093/ije/dyp374

Gimnig, J. E., Ombok, M., Kamau, L. and Hawley, W. A. (2001) Characteristics of larval anopheline (Diptera: Culicidae) habitats in Western Kenya. Fournal of Medical Entomology 38, 282-288. doi: 10.1603/00222585-38.2.282.

Hashizume, M., Terao, T. and Minakawa, N. (2009). The Indian Ocean Dipole and malaria risk in the highlands of western Kenya. Proceedings of the National Academy of Sciences, USA 106, 1857-1862. doi: 10.1073/ pnas.0806544106

Hay, S. I., Myers, M. F., Burke, D. S., Vaughn, D. W., Endy, T., Ananda, N., Shanks, G. D., Snow, R. W. and Rogers, D. J. (2000). Etiology of interepidemic periods of mosquito-borne disease. Proceedings of the National Academy of Sciences, USA 97, 9335-9339. doi: 10.1073/ pnas.97.16.9335.

Hay, S. I., Noor, A. M., Simba, M., Busolo, M., Guyatt, H. L., Ochola, S. A. and Snow, R. W. (2002a). Clinical epidemiology of malaria in the highlands of western Kenya. Emerging Infectious Diseases 8, 543-548. Hay, S. I., Simba, M., Busolo, M., Noor, A. M., Guyatt, H. L., Ochola, S. A. and Snow, R. W. (2002b). Defining and detecting malaria epidemics in the highlands of western Kenya. Emerging Infectious Diseases $\mathbf{8}$ 555-562.

John, C. C., Ouma, J.H., Sumba, P. O., Hollingdale, M. R., Kazura, J. W. and King, C. L. (2002). Lymphocyte proliferation and antibody responses to Plasmodium falciparum liver-stage antigen-1 in a highland area of Kenya with seasonal variation in malaria transmission. The American Fournal of Tropical Medicine and Hygiene 66, 372-378.

John, C. C., Riedesel, M.A., Magak, N. G., Lindblade, K. A., Menge, D. M., Hodges, J.S., Vulule, J. M. and Akhwale, W. (2009) Possible interruption of malaria transmission, Highland Kenva, 2007-2008. Emerging Infectious Diseases 15, 1917-1924. doi: 10.3201/eid1512.090627. Kaneko, A., Taleo, G., Kalkoa, M., Yamar, S., Kobayakawa, T. and Björkman, A. (2000). Malaria eradication on islands. The Lancet 356, 15601564

Kaneko, A., Taleo, G., Kalkoa, M., Yaviong, J., Reeve, P. A., Ganczakowski, M., Shirakawa, C., Palmer, K., Kobayakawa, T. and Björkman, A. (1998). Malaria epidemiology, glucose 6-phosphate dehydrogenase deficiency and human settlement in the Vanuatu Archipelago. Acta Tropica 70, 285-302. doi: 10.1016/s0001-706x(98)00035-7.

Koenraadt, C. J. M., Paaijmans, K. P., Schneider, P., Githeko, A. K. and Takken, W. (2006). Low larval vector survival explains unstable malaria in the western Kenya highlands. Tropical Medicine \& International Health 11, 1195-1205. doi: 10.1111/j.1365-3156.2006.01675.x.

Levins, R. (2006). Strategies of abstraction. Biology \& Philosophy 21, 741755. doi: 10.1007/s10539-006-9052-8

Lewontin, R. C. and Levins, R. (1989). On the characterization of density and resource availability. American Naturalist 134, 513-524.

Lindblade, K. A., Eisele, T.P., Gimnig, J. E., Alaii, J. A., Odhiambo, F., ter Kuile, F. O., Hawley, W.A. Wannemuehler, K.A., Phillips-Howard, P.A., Rosen, D. H. Nahlen, B. L., Terlouw, D. J., Adazu, K., Vulule, J.M. and Slutsker, L. (2004). Sustainability of reductions in malaria transmission and infant mortality in Western Kenya with use of insecticide-treated bednets. FAMA: The Fournal of the American Medical Association 291 2571-2580. doi: 10.1001/jama.291.21.2571.

Lindblade, K. A., Katungu, J. and Wilson, M. L. (2001). Fever and malaria in highland Uganda. Transactions of the Royal Society of Tropical Medicine and Hygiene 95, 502-503.

Lindblade, K.A., Walker, E.D., Onapa, A.W., Katungu, J. and Wilson, M. L. (1999). Highland malaria in Uganda: prospective analysis of an epidemic associated with El Niño. Transactions of the Royal Society of Tropical Medicine and Hygiene 93, 480-487.

Lindblade, K. A., Walker, E.D., Onapa, A. W., Katungu, J. and Wilson, M.L. (2000). Land use change alters malaria transmission parameters by modifying temperature in a highland area of Uganda. Tropical Medicine \& International Health 5, 263-274.

Lindsay, S. W. and Birley, M. H. (1996). Climate change and malaria transmission. Annals of Tropical Medicine and Parasitology 90, 573-588.

Lindsay, S. W. and Martens, W. J. M. (1998). Malaria in the African highlands: past, present and future. Bulletin of the World Health Organization, 76, 33-45.

McCallum, H., Barlow, N. and Hone, J. (2001). How should pathogen transmission be modelled? Trends in Ecology E Evolution 16, 295-300. 
Menge, D. M., Ernst, K. C., Vulule, J. M., Zimmerman, P. A., Guo, H. and John, C. C. (2008). Microscopy underestimates the frequency of Plasmodium falciparum infection in symptomatic individuals in a low transmission highland area. The American Fournal of Tropical Medicine and Hygiene 79, 173-177.

Minakawa, N., Munga, S., Atieli, F., Mushinzimana, E., Zhou, G., Githeko, A. K. and Yan, G. (2005a). Spatial distribution of anopheline larval habitats in western Kenyan highlands: effects of land cover types and topography. The American Fournal of Tropical Medicine and Hygiene 73, 157-165.

Minakawa, N., Omukunda, E., Zhou, G., Githeko, A. and Yan, G. (2006). Malaria vector productivity in relation to the highland environment in Kenya. American Fournal of Tropical Medicine and Hygiene 75, 448-453. doi: 75/3/448 [pii].

Minakawa, N., Sonye, G., Mogi, M., Githeko, A. and Yan, G. Y. (2002). The effects of climatic factors on the distribution and abundance of malaria vectors in Kenya. Fournal of Medical Entomology 39, 833-841.

Minakawa, N., Sonye, G. and Yan, G. (2005b). Relationships between occurrence of Anopheles gambiae s.l. (Diptera: Culicidae) and size and stability of larval habitats. Fournal of Medical Entomology 42, 295-300.

Molineaux, L., Storey, J., Cohen, J.E. and Thomas, A. (1980). A longitudinal study of human malaria in the west African savanna in the absence of control measures: relationships between different Plasmodium species, in particular $P$. falciparum and $P$. malariae. The American fournal of Tropical Medicine and Hygiene 29, 725-737.

Munyekenye, O.G., Githeko, A.K., Zhou, G., Mushinzimana, E., Minakawa, N. and Yan, G. (2005). Spatial analysis of Plasmodium falciparum infections in western Kenya Highlands. Emerging Infectious Diseases 10, 1571-1577.

Ofulla, A. V., Moormann, A. M., Embury, P. E., Kazura, J. W., Sumba, P. O. and John, C. C. (2005). Age-related differences in the detection of Plasmodium falciparum infection by PCR and microscopy, in an area of Kenya with holo-endemic malaria. Annals of Tropical Medicine and Parasitology 99, 431-435. doi: 10.1179/136485905x36316.

Paaijmans, K. P., Wandago, M. O., Githeko, A. K. and Takken, W. (2007). Unexpected high losses of Anopheles gambiae larvae due to rainfall. PLoS ONE, 2, e1146. doi: 10.1371/journal.pone.0001146.

Pascual, M. and Bouma, M. J. (2009). Do rising temperatures matter? Ecology 90, 906-912.

Pascual, M., Cazelles, B., Bouma, M. J., Chaves, L. F. and Koelle, K. (2008). Shifting patterns: malaria dynamics and rainfall variability in an African highland. Proceedings of the Royal Society of London, B 275, 123 132. doi: $10.1098 / \mathrm{rspb} .2007 .1068$

Patz, J. A. and Olson, S. H. (2006). Malaria risk and temperature: influences from global climate change and local land use practices. Proceedings of the National Academy of Sciences, USA 103, 5635-5636.
Ploberger, W., Krämer, W. and Kontrus, K. (1989). A new test for structural stability in the linear regression model. Fournal of Econometrics $\mathbf{4 0}$, 307-318.

Prothero, R. M. (1965). Migrants and Malaria. Longmans, London, UK. Reiter, P. (2008). Global warming and malaria: knowing the horse before hitching the cart. Malaria fournal 7, S3.

Saji, N. H., Goswami, B. N., Vinayachandran, P. N. and Yamagata, T. (1999). A dipole mode in the tropical Indian Ocean. Nature, London 401, 360-363.

Saji, N.H. and Yamagata, T. (2003). Possible impacts of Indian Ocean Dipole mode events on global climate. Climate Research 25, 151-169.

Shanks, G., Biomndo, K., Hay, S. and Snow, R. (2000). Changing patterns of clinical malaria since 1965 among a tea estate population located in the Kenyan highlands. Transactions of the Royal Society of Tropical Medicine and Hygiene 94, 253-55.

Shanks, G. D., Hay, S. I., Omumbo, J. A. and Snow, R. W. (2005). Malaria in Kenya's western highlands. Emerging Infectious Diseases 11, 1425-1432.

Shanks, G. D., Hay, S. I., Stern, D. I., Biomndo, K. and Snow, R. W. (2002). Meteorologic influences on Plasmodium falciparum malaria in the highland tea estates of Kericho, western Kenya. Emerging Infectious Diseases 8, 1404-1408.

Shumway, R.H. and Stoffer, D. S. (2000). Time Series Analysis and its Applications. Springer, New York, USA.

Silver, J. B. (2008). Mosquito Ecology: Field Sampling Methods, 3rd Edn. Springer, New York, USA

Teklehaimanot, H.D., Lipsitch, M., Teklehaimanot, A. and Schwartz, J. (2004). Weather-based prediction of Plasmodium falciparum malaria in epidemic-prone regions of Ethiopia I. Patterns of lagged weather effects reflect biological mechanisms. Malaria Fournal 3, 41. doi: 10.1186/ 1475-2875-3-41

Verschuren, D., Johnson, T. C., Kling, H. J., Edgington, D. N., Leavitt, P. R., Brown, E. T., Talbot, M. R. and Hecky, R. E. (2002). History and timing of human impact on Lake Victoria, East Africa. Proceedings of the Royal Society of London, B 269, 289-294. doi: 10.1098/ rspb.2001.1850.

Zhou, G., Afrane, Y. A., Vardo-Zalik, A. M., Atieli, H., Zhong, D. Wamae, P., Himeidan, Y.E., Minakawa, N., Githeko, A. K. and Yan, G. (2011). Changing patterns of malaria epidemiology between 2002 and 2010 in Western Kenya: the fall and rise of malaria. PLoS ONE 6 , e20318

Zhou, G., Minakawa, N., Githeko, A. K. and Yan, G. Y. (2004) Association between climate variability and malaria epidemics in the East African highlands. Proceedings of the National Academy of Sciences, USA 101, 2375-2380. doi: 10.1073/pnas.0308714100. 